Brit. Heart F., 1966, 28, 646.

\title{
Anomalous Left Coronary Artery Arising from the Pulmonary Artery
}

\author{
A report on two cases with successful surgical therapy
}

\author{
G. LOSEKOOT, E. J. RENAUD, N. G. MEYNE, AND R. Th. VAN DAM \\ From the University Department of Pediatrics, and the Department of Roentgenology, Binnengasthuis, Amsterdam, and \\ the University Departments of Surgery and of Cardiology, Wilhelmina-Gasthuis, Amsterdam
}

An anomalous origin of coronary arteries from the pulmonary artery is relatively rare. The following variations may occur:

(a) Anomalous origin of the left coronary artery; this is the most important condition from a clinical point of view, and will be discussed presently.

(b) The right coronary artery has its origin from the pulmonary artery. Usually sufficient collaterals develop to prevent cardiac failure; the survival chances of these patients are equal to those of normal children (Jordan, Dry, and Edwards, 1950; Cronk, Sinclair, and Rigdon, 1951).

(c) Both coronary arteries arise from the pulmonary artery. This condition is not compatible with extrauterine life; patients survive birth for a few hours to days only (Soloff, 1942; Tedeschi and Helpern, 1954; Alexander and Griffith, 1956; Keith, Rowe, and Vlad, 1958; Colmers and Siderides, 1963).

(d) Accessory coronary artery arising from the pulmonary artery, and both left and right coronary arteries originate from the aorta (Feriz, 1923; Liebman et al., 1963). This condition has been regarded as relatively harmless. Recently, however, it has been demonstrated that the accessory coronary artery may function as an arteriovenous shunt, which may induce ischæmia in a relatively large area of the left ventricle (Liebman et al., 1963).

In cases with an anomalous origin of the left coronary artery from the pulmonary artery, the symptoms and life-expectancy depend largely on the number of collaterals that are present between right and left coronary arteries. For this reason, in the past, cases have been divided into an "adult" and

Received August 31, 1965. an "infantile" type. In the "adult" type extensive collaterals have developed. Life expectancy may be normal. However, sudden death may occur at school age or later (Gouley, 1950; Agustsson, Gasul, and Lundquist, 1962); then the anomaly is an unexpected finding at necropsy. The first clinical diagnosis of the "adult" type was made by Lampe and Verheugt in 1960 in a boy in whom a continuous murmur was audible, as in almost every patient with this anomaly. Confusion with a patent ductus arteriosus is possible; also, the combination of both anomalies has been described (Alexander and Griffith, 1956; Jurishica, 1957). Where there is paucity of collaterals, the "infantile" type develops, known as the Bland-White-Garland syndrome (Bland, White, and Garland, 1933). These patients are seriously ill from shortly after birth and usually die from cardiac failure before the end of the first year.

Recently it has been suggested by Edwards (1964) and Nadas, Gamboa, and Hugenholtz (1964) that this division into two types is too rigid, and that transitional forms occur.

In this paper we describe two cases of the "infantile" type, which successfully underwent surgical therapy.

\section{CASE Reports}

Case 1. A girl, weighing 4250 g., was born on July 19,1961 , after an uneventful pregnancy. At the age of 11 months she was admitted to a hospital, because of recurrent attacks of bronchitis. At that time the heart was greatly enlarged at physical examination. The heart sounds were normal, and no cardiac murmurs were heard. One week later she suddenly developed a left-sided 646 


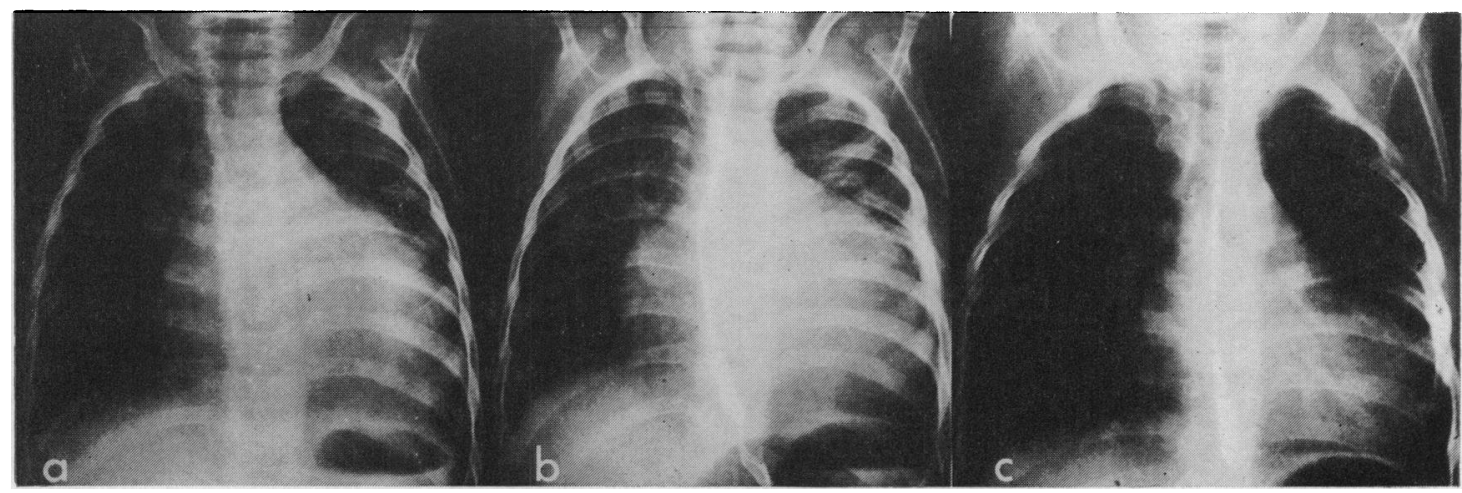

FIG. 1.-Radiograph of Case 1, (a) before operation, (b) shortly after operation, (c) one year after operation.

process. Two weeks later she was transferred to the pædiatric department of the University of Amsterdam.

Radiological examination. Marked dilatation of the heart, mainly of the left ventricle: CT ratio 0.66 (Fig. 1).

Electrocardiogram. Deep and wide $Q$ waves and negative T waves in leads I, AVL, V5, and V6 (Fig. 2A).

Aortography. Normal opacification of a large right coronary artery and some branches; also secondary filling of the left coronary artery via collaterals, and some contrast material was seen at the expected location of the pulmonary trunk.

Operation. Thoracotomy was performed in the 5th left intercostal space (August 1, 1962), and the pericardium was opened anteriorly to the phrenic nerve; it contained $50 \mathrm{ml}$. of a clear yellow fluid. The heart was greatly enlarged; near the apex, a pale area measuring approximately $3 \times 4 \mathrm{~cm}$. did not participate in the contractions of the left ventricle. Over the outflow tract of the right ventricle several tortuous vessels, probably collaterals between left and right coronary arteries, were present.

Because of the dilatation of the left ventricle, the origin of the left coronary artery was at first obscured. After careful exploration, its main trunk of $3 \mathrm{~mm}$. length could be identified, occupying the normal position, but originating from the pulmonary artery instead of from the aorta.

After test clamping during 3 minutes was tolerated well, the vessel was doubly ligated near its origin, and talcum powder was put on the surface of the left ventricle. The post-operative course was uneventful; digitalis medication was continued.

Follow-up. The child improved gradually; exercise tolerance increased; she had a few recurrences of bronchitis, but these were less serious than previously.

In 2 years the girl gained $5350 \mathrm{~g}$. weight and increased $19 \mathrm{~cm}$. in height. She learned to walk.

On radiological examination the heart became much smaller; the CT ratio decreased to 0.60 (Fig. 1).

In the electrocardiogram, the $T$ waves in leads $I$ and AVL became less negative and negative-positive in V5 and V6. The QR ratio was not changed and abnormal
$Q$ waves were still present in præcordial leads over a large area of the left ventricle (Fig. 2B).

Case 2 A girl was born in December, 1961, weighing 3000 g., after an uneventful pregnancy. There was one earlier still birth of an anencephalic child.

During the first month there were no difficulties with breast-feeding, though she did not thrive. At 2 months she was not feeding well and had gained no weight; in addition she appeared to be short of breath and was perspiring frequently. On June 24, 1962, she was admitted to the pædiatric department, because of vomiting and lack of appetite.

Physical examination revealed a child in poor condition; body weight $5300 \mathrm{~g}$., length $63 \mathrm{~cm}$. She was dyspnœic at the slightest exertion. The pulse rate was 120 a minute; regular, equal. There were no signs of cardiac failure. On percussion the heart was very enlarged to the left. There were normal heart sounds and a grade II protosystolic murmur at the lower left sternal border.

Radiological examination revealed a greatly enlarged heart, mainly due to dilatation of the left ventricle; the CT ratio was 0.62 .

Electrocardiogram. There were very deep and wide $Q$ waves and negative $T$ waves in leads I, AVL, V5, and V6. There was slight ST depression in V2, V3, and V4 (Fig. 3A).

Aortography was not done because it was impossible to pass a sufficiently large catheter into the brachial artery.

At operation on August 9, 1962, thoracotomy was performed via the 4 th left intercostal space; the pericardium contained $75 \mathrm{ml}$. clear fluid. The left ventricle was much enlarged; near the apex a pale area measuring approximately $2 \times 3 \mathrm{~cm}$. did not participate in the contractions of the left ventricle.

The diameter of the descending branch of the left coronary artery was larger than normal; several collaterals were present on the outflow tract of the right ventricle.

In the corner between left ventricle, pulmonary artery, and left atrium, the main trunk of the left coronary 


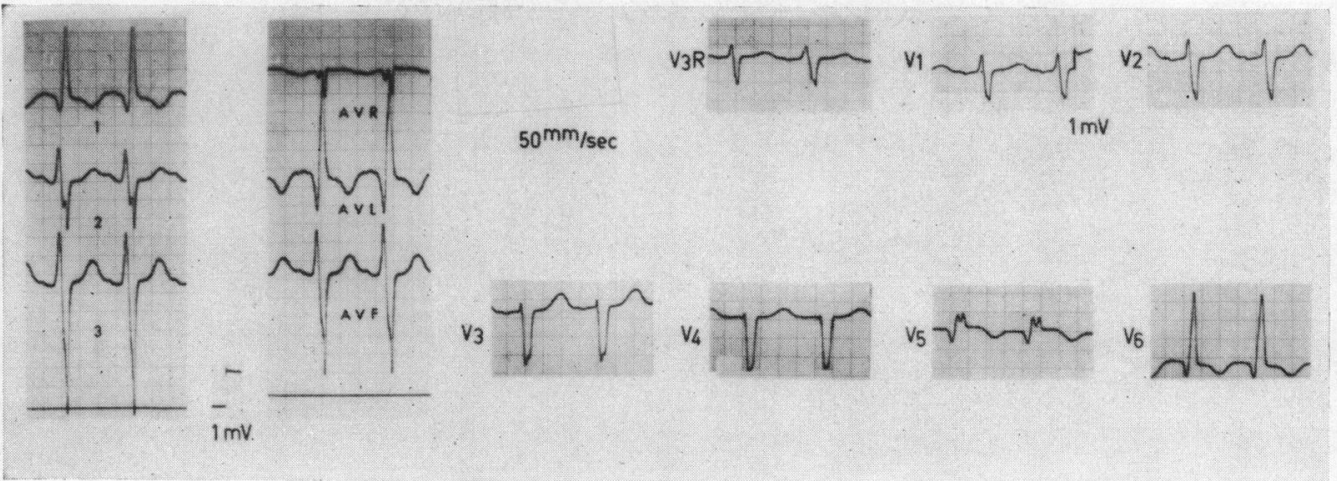

A

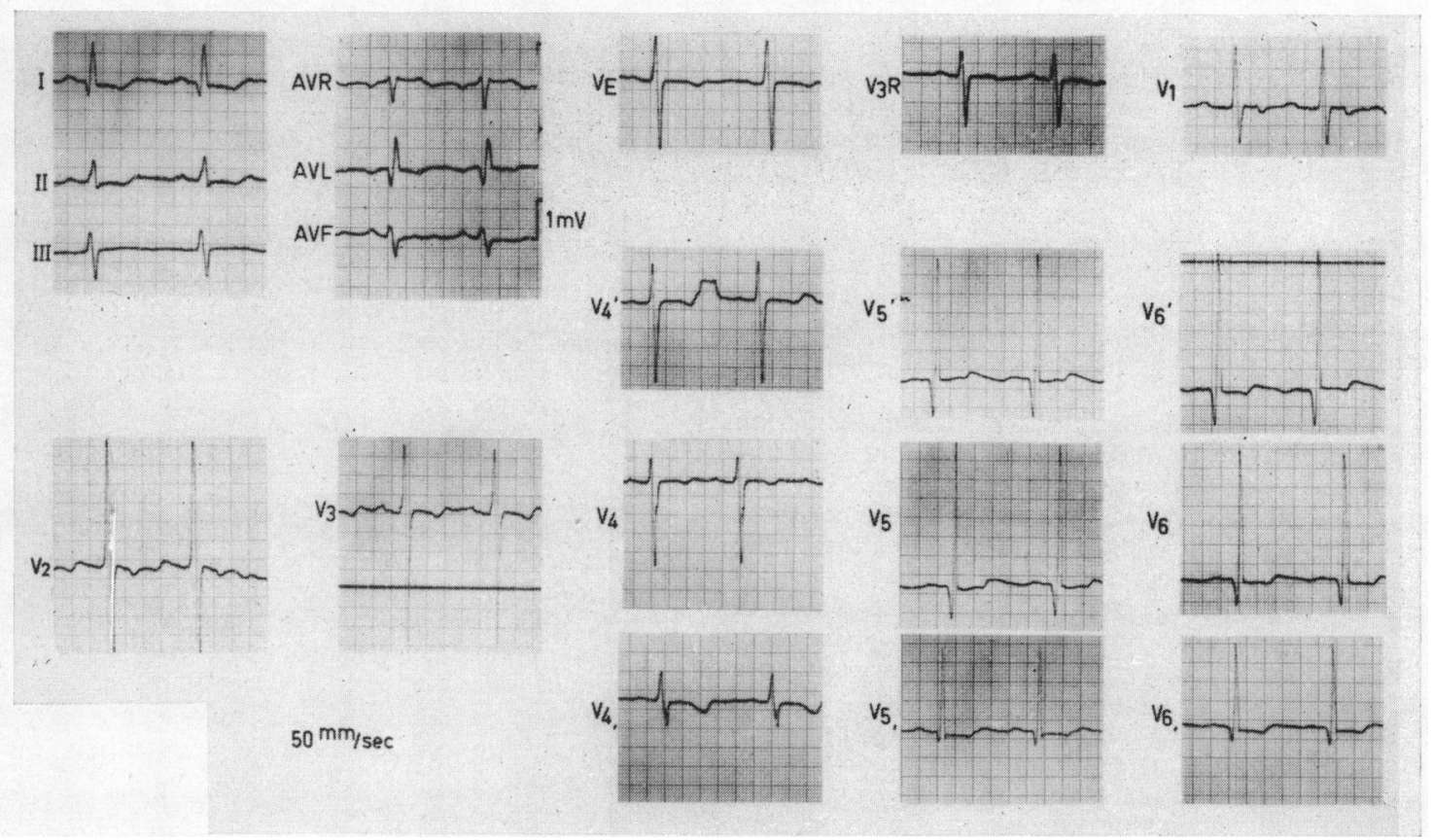

B

Fig. 2-(A) Pre-operative electrocardiogram of Case 1, at the age of 12 months. Præcordial leads recorded at half normal sensitivity. Note deep and wide $Q$ waves, and negative $T$ waves in leads I, AVL, V5, and V6.(B) Electrocardiogram at the age of nearly 3 years; 23 months after operation. The complexes from intercostal spaces above and below the fourth intercostal space were recorded. The $T$ waves in leads I and AVL became less negative and negative-positive in V5 and V6. Abnormal $Q$ waves are still present in præcordial leads over a large area of the left ventricle.

artery was visible; it was $4 \mathrm{~mm}$. long and originated from the posterior side of the pulmonary artery.

A test clamping period of 3 minutes was tolerated well; during this period the pulsations in the descending branch of the left coronary artery became more forceful. Subsequently the left coronary artery was doubly ligated near its origin, and talcum powder was put on the surface of the left ventricle. Before and after ligation of the abnormal left coronary artery, unipolar epicardial leads were recorded from two sites in the pale area of the left ventricle supplied by this vessel (Fig. 4).

The post-operative course was uneventful; the digitalis medication was continued.

Follow up. Initially the child did not improve, but after a few months she was feeding better and gained $6000 \mathrm{~g}$. weight in a period of 22 months. The exercise tolerance increased, and the child learned to walk. 


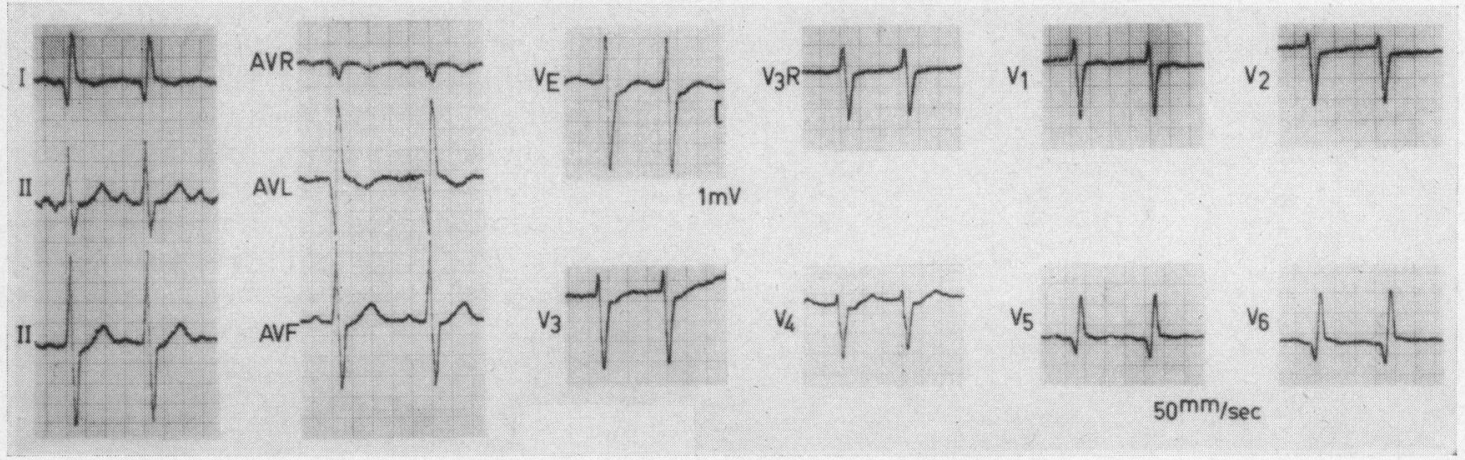

A

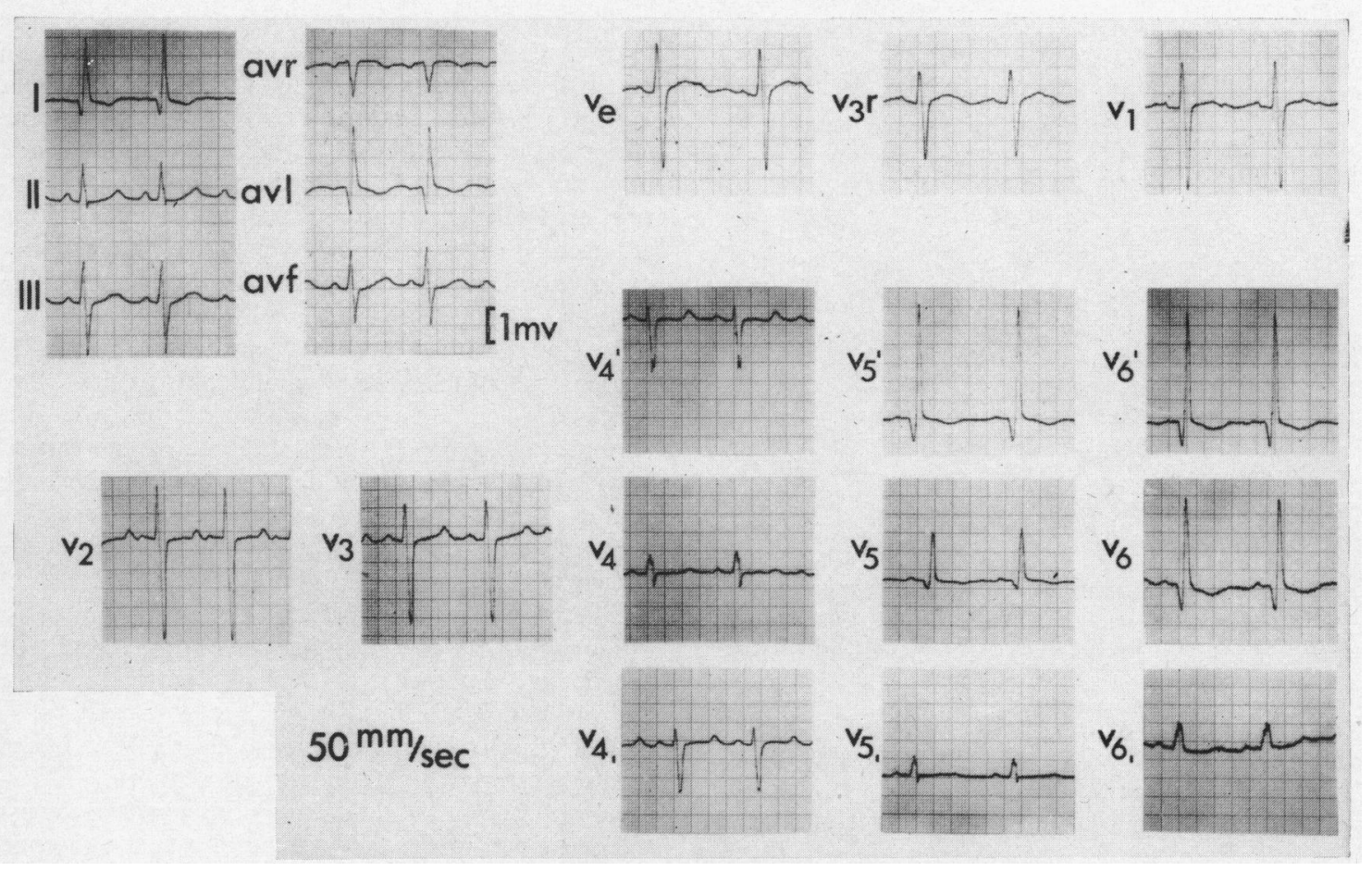

B

Fig. 3-(A). Pre-operative electrocardiogram of Case 2 at the age of $6 \frac{1}{2}$ months. Præcordial leads are recorded at half normal sensitivity. Note deep and wide $Q$ waves and negative $T$ waves in leads $I, A V L$, V5, and V6. There is slight ST depression in V2, V3, and V4. (B). Electrocardiogram taken at $27 \frac{1}{2}$ months of age, 20 months after operation. An abnormal $Q$ remains in leads $I, A V L, V 5$ and V6; however, in these leads the $\mathbf{Q} / \mathbf{R}$ ratio has decreased.

Radiological examinations showed that the dilatation of the heart increased in the first post-operative month, but decreased later on. CT ratios were 0.64 and 0.54 in September 1962 and May 1964, respectively.

In the electrocardiogram, an abnormal $Q$ wave remained in leads I, AVL, V5, and V6. The $Q / R$ ratio of these leads decreased (Fig. 3B). 


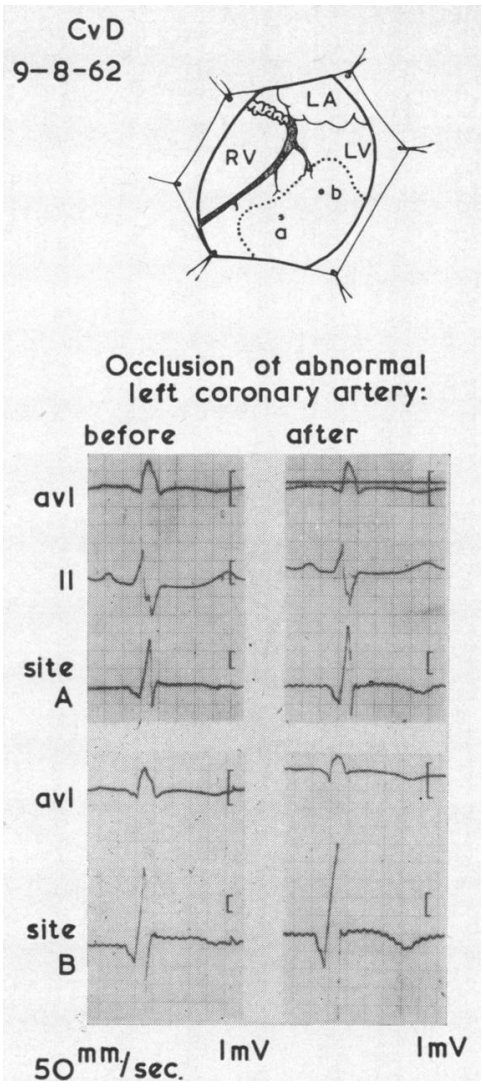

Fig. 4.-Electrocardiogram (Case 2) and unipolar epicardial leads from two sites ( $a$ and $b$ in diagram above) on the area supplied by the anterior descending branch of the left coronary artery, before and during test clamping of the left coronary artery near its anomalous origin from the pulmonary trunk. During occlusion no essential changes in the activation occurred.

physical examination reveals aspecific symptoms, normal blood pressure, and a strong tendency exists to develop cardiac failure.

From all the published reports it appears that in the infantile type the babies are in good condition immediately after birth; after a while, usually at the age of 3 months, difficulties arise. Feeding becomes more difficult, infants stop growing, they get short of breath, perspire excessively and look pale. Often, they cry while being fed, and this has been attributed to pain caused by myocardial ischæmia. Upper respiratory infections are common, and frequently atelectasis occurs (Proescher and Baumann, 1944; Eidlow and Mackenzie, 1946).

On physical examination, cardiac enlargement is most striking, and gallop rhythm is a common finding. Usually, murmurs are absent; in some cases a systolic murmur can be heard, which either arises in the grossly dilated right coronary artery (Liebman et al., 1963), or is due to mitral insufficiency (Liebman et al., 1963; Noren et al., 1964) which may be caused by malfunctioning of a papillary muscle of the left ventricle (Noren et al., 1964).

Radiographs demonstrate conspicuous dilatation of the left ventricle and left atrium.

The electrocardiogram is typical; the most important signs are (Burch and DePasquale, 1962): (a) mean electrical axis in the frontal plane between $60^{\circ}$ and $90^{\circ}$; (b) deep and broad $Q$ in leads I, AVL, V4-V6; (c) T wave inversion in leads I, V5, and V6; (d) high $\mathrm{R}$ wave in $\mathrm{V} 6$ and deep $\mathrm{S}$ in $\mathrm{V} 1$; (e) during feeding, ST-T changes may occur; (f) disturbances of conduction are rare. This typical electrocardiographic pattern resembles that of antero-lateral wall infarction.

The most striking feature is the presence of large $Q$ waves in leads that record the epicardial potential of the antero-lateral portion of the left ventricle: $I, A V L, V 4-V 6$. That these $Q$ waves originate in the abnormal part of the left ventricle is demonstrated in the unipolar epicardial leads taken during operation on Case 2 from the greyish white area on the anterior surface of the left ventricle, that did not contract vigorously like the rest of the left ventricle (Fig. 4).

In these leads a broad $Q$ wave of 0.35 sec. is present, measured from beginning to nadir. The intrinsic deflection occurs approximately $0.65 \mathrm{sec}$. after the onset of $Q$. This indicates a late arrival of epicardial excitation in the area involved, because of slow conduction through the infarcted area by way of surviving intra-infarction muscle cells (Durrer, Van Lier, and Büller 1964).

The high $R$ wave in V6 and the deep $S$ wave in V1 are probably caused by (relative) hypertrophy of the postero-basal part of the left ventricle (Burch and DePasquale, 1962).

Aortography usually shows clearly the right coronary artery which is increased in calibre. However, absence of direct filling of the left coronary artery during aortography does not prove the absence of this vessel. If a sufficient number of collaterals between the right and left coronary arteries exists, retrograde filling of the left coronary artery and of the main trunk of the pulmonary artery may occur.

Venous angiocardiography demonstrates the dilatation of the left side of the heart. By selective injection of contrast medium into the pulmonary artery, the anomalous origin of the left coronary artery is demonstrated only in cases with raised pulmonary arterial pressure (Armer et al., 1963; Edwards, 1964).

The prognosis is very poor without operation; usually the children die before the end of the first year, and most of them before the age of 6 months, 
from progressive cardiac failure or recurrent infections of the upper respiratory tract. McKinley, Andrews, and Neill (1951) observed rupture of the myocardium. The anatomical abnormalities are limited to the area supplied by the left coronary artery; they concern mainly the anterior wall of the much dilated left ventricle. In the acute phase, necrosis and degenerative changes of the myocardium occur; these are followed by fibrosis and frequently end in calcification (Kaunitz, 1947). The left ventricular wall becomes thin; at the apex, where the changes are most intensive, its diameter sometimes measures $1 \mathrm{~mm}$. only. The trabeculæ and papillary muscles are flattened. The endocardium and valve leaflets usually are thickened and whitish in appearance because of fibro-elastosis (Keith, 1959). There is little doubt that local coronary circulatory insufficiency plays a major role in the development of this morphological and functional alteration.

The anoxæmia has been attributed to two factors: (1) low oxygen content of the blood derived from the pulmonary artery; and (2) relatively low pressure in the left coronary artery.

Following a lead given by Brooks (1885), Edwards in 1958 assumed the presence of a shunt from the right to the left coronary artery, and a reversal of blood flow in the left coronary artery which then drained into the pulmonary artery. This shunt functions, therefore, as an arteriovenous fistula between aorta and pulmonary artery, and has been demonstrated by several investigators (Apley, Horton, and Wilson, 1957; Case et al., 1958; Cohen and Siew, 1959; Rowe and Young, 1960; Sabiston, Neill, and Taussig, 1960; Beuren and Hoffmeister, 1963).

Recently, Edwards (1964) postulated a transitional phase in these cases between two main phases of blood flow in the left coronary artery. According to his views development may be as follows:

(1) During intrauterine life and immediately after birth the pressure in the pulmonary artery and in the aorta are equal, and the area supplied by the anomalous left coronary artery derives its blood from the pulmonary artery. Although this blood is undersaturated, anoxæmia does not necessarily exist.

(2) The postulated transitional phase: the pressure in the pulmonary artery drops below that in the aorta, and as a consequence the blood supply of the area involved decreases and becomes insufficient. During this phase, symptoms of myocardial ischæmia may start and a condition comparable to myocardial infarction may develop.

(3) A network of collaterals has developed between left and right coronary arteries by which blood is directed from the aorta into the pulmonary artery. Now the involved myocardium receives its blood from the normally-arising right coronary artery.
The myocardial ischæmia in this phase should be related to the escape of coronary arterial blood through the fistula.

Apparently two factors determine the occurrence of symptoms: (a) the quantity of blood that is delivered to the myocardium; and (b) the volume of blood shunted via the arterio-venous fistula. Probably these two factors are closely interdependent in some way. In discussions on the genesis of the consequences in this condition the role of the collateral circulation is an essential feature. So far it is not clear to what degree these collaterals are congenitally present or have developed at a later stage.

During phase (1) the patient experiences no difficulties; these arise at a later stage, when the blood supply to the myocardium becomes insufficient because the pressure in the pulmonary artery decreases to a lower level than in the aorta. Probably, ischæmia occurs and is followed by local fibrosis, as in infarction, whenever the area is not supplied through a collateral circulation derived from the right coronary artery. If, however, in this critical phase, enough collaterals are present, the myocardium in this area may have sufficient blood supply. These collaterals can also shunt blood in a reverse direction into the pulmonary artery. In a later stage of development this shunt may increase and can cause cardiac insufficiency, generally following puberty. Between these two possible extremes, the infantile and the adult type, respectively, a wide spectrum of intermediate forms may occur (Rudolph et al., 1963; Edwards, 1964; Nadas et al., 1964). In both our patients the electrocardiogram demonstrated an antero-lateral myocardial infarction, and during operation a part of the anterior surface of the left ventricle appeared to be fibrosed and pulsated less vigorously than the remaining left ventricle.

In addition, a shunt existed between the right coronary artery and the pulmonary artery. In the first of our cases this shunt was demonstrated by angiocardiography; in both, the amplitude of the pulsations in the anterior descending branch was increased following ligation of the left coronary artery near the pulmonary artery. Observations of others have demonstrated that following ligation the pressure in the left coronary artery rises (Sabiston et al., 1963), and it may be assumed that the blood supply to the myocardium in this region increases. It seems improbable that this has an important effect on the infarcted area itself. The improvement in the condition of these patients that follows ligation is probably caused by an improvement in the perfusion of the neighbouring areas. In these regions the myocardium had been insufficiently 
supplied with blood, and as a consequence its contractility may have been impaired. It is remarkable, however, that the insufficient blood supply rarely causes persisting electrocardiographic signs of injury. As the experiences of Nadas et al. (1964) and of Kuzman, Yuskis, and Carmichael (1959) demonstrate, ligation of the abnormal coronary artery should be done with caution because, during the stage in which the area involved still is supplied from the pulmonary artery, an acute infarction may follow the ligation. When pre-operative investigations do not prove the presence of a shunt from the right coronary artery via the left coronary artery to the pulmonary artery, a test clamping of the left coronary artery should be performed; in both our cases this was well tolerated.

Apparently, also in the adult type occlusion of the anomalous coronary artery may give rise to complications (Massih, Lawler, and Vermillion, 1963).

It is not yet possible to estimate the long-term prognosis following ligation of the coronary artery in our cases; we feel, however, that the considerable improvement in our two patients warrants a somewhat optimistic view.

\section{SUMMARY}

Two cases are described of anomalous origin of the left coronary artery from the pulmonary trunk in infants. Diagnosis was established at the ages of 6 and 11 months, on the typical clinical picture consisting of onset of symptoms at the age of 3 months, cardiac enlargement, and an electrocardiographic pattern of antero-lateral myocardial infarction. In one case this diagnosis was confirmed before operation by means of angiocardiography.

Ligation of the abnormal left coronary artery was performed in both infants, the condition of both improving conspicuously following the operation. In one case, direct unipolar epicardial electrocardiographic leads displaying an abnormal $Q$ wave were taken from the fibrotic area of the left ventricle before and after ligation of the left coronary artery.

The pathogenesis of this condition and its hæmodynamic and electrocardiographic consequences are discussed.

We should like to thank Professor Dr. D. Durrer for his advice, especially on the problem of electrocardiography.

\section{ADDENDUM}

Since this paper was completed the authors have seen two further cases of anomalous origin of the left coronary artery. A girl, aged 5 months, was admitted to the department of pædiatrics with the typical signs of severe mitral insufficiency. She died before the correct diagnosis could be made.
The second child, a girl of $3 \frac{1}{2}$ years, was admitted to the pædiatric department with the clinical picture of a ventriculer septal defect; the electrocardiogram showed the pattern of an antero-lateral infarction. Right-sided heart catheterization revealed a small ventricular septal defect. Selective injection of contrast material into the right coronary artery gave secondary filling of the left coronary artery and of the pulmonary trunk. The anomalous left coronary artery was ligated; the septal defect was not closed. The post-operative course was uneventful.

\section{REFERENCES}

Agustsson, M. H., Gasul, B. M., and Lundquist, R. (1962). Anomalous origin of the left coronary artery from the pulmonary artery (adult type). A case report. Pediatrics, 29, 274.

Alexander, R. W., and Griffith, G. C. (1956). Anomalies of the coronary arteries and their clinical significance. Circulation, 14, 800.

Apley, J., Horton, R. E., and Wilson, M. G. (1957). The possible role of surgery in the treatment of anomalous left coronary artery. Thorax, 12, 28.

Armer, R. M., Shumacker, H. B., Lurie, P. R., and Fisch, C. (1963). Origin of the left coronary artery from the pulmonary artery without collateral circulation. Report of a case with suggested surgical correction. Pediatrics, $32,588$.

Beuren, A. J., and Hoffmeister, H. E. (1963). Diagnose, Hämodynamik und chirurgische Therapie des Fehlabgangs der linken Koronararterie von der Arteria pulmonalis. Z. Kreisl.-Forsch., 52, 1088.

Bland, E. F., White, P. D., and Garland, J. (1933). Congenital anomalies of the coronary arteries: report of an unusual case associated with cardiac hypertrophy. Amer. Heart $\mathcal{F}$., 8, 787.

Brooks, H. St John (1885). Two cases of an abnormal coronary artery of the heart arising from the pulmonary artery. F. Anat. Physiol., 20, 26.

Burch, G. E., and DePasquale, N. P. (1962). The electrocardiogram in certain anomalies of the coronary arteries. Amer. Heart f., 64, 38.

Case, R. B., Morrow, A. G., Stainsby, W., and Nestor, J. O. (1958). Anomalous origin of the left coronary artery; the physiologic defect and suggested surgical treatment. Circulation, 17, 1062.

Cohen, H., and Siew, S. (1959). Aberrant left coronary artery. Circulation, 20, 918.

Colmers, R. A., and Siderides, C. I. (1963). Anomalous origin of both coronary arteries from pulmonary trunk. Myocardial infarction in otherwise normal heart. Amer. F. Cardiol, 12, 263.

Cronk, E. S., Sinclair, J. G., and Rigdon, R. H. (1951). An anomalous coronary artery arising from the pulmonary artery. Amer. Heart f., 42, 906.

Durrer, D., Van Lier, A. A. W., and Büller, J. (1964). Epicardial and intramural excitation in chronic myocardial infarction. Amer. Heart F., 68, 765.

Edwards, J. E. (1958). Editorial. Anomalous coronary arteries with special reference to arteriovenous-like communications. Circulation, 17, 1001.

- (1964). The direction of blood flow in coronary arteries arising from the pulmonary trunk. Circulation, 29, 163.

Eidlow, S., and Mackenzie, E. R. (1946). Anomalous origin of the left coronary artery from the pulmonary artery; report of a case diagnosed clinically and confirmed by necropsy. Amer. Heart f., 32, 243. 
Feriz, H. (1923). Accessorische kransarterien van het hart uit de longslagader. Ned. T. Geneesk., 67, pt. 1, p. 567.

Gouley, B. A. (1950). Anomalous left coronary artery arising from the pulmonary artery (adult type). Amer. Heart f., 40, 630.

Jordan, R. A., Dry, T. J., and Edwards, J. E. (1950). Cardiac clinics; anomalous origin of the right coronary artery from the pulmonary trunk. Proc. Mayo Clin., 25, 673.

Jurishica, A. J. (1957). Anomalous left coronary artery. Amer. Heart F., 54, 429.

Kaunitz, P. E. (1947). Origin of left coronary artery from pulmonary artery. Review of the literature and report of two cases. Amer. Heart F., 33, 182.

Keith, J.D. (1959). The anomalous origin of the left coronary artery from the pulmonary artery. Brit. Heart $\mathcal{f}$., 21, 149.

-, Rowe, R. D., and Vlad, P. (1958). Heart Disease in Infancy and Childhood. Macmillan, New York.

Kuzman, W. J., Yuskis, A. S., and Carmichael, D. B. (1959). Anomalous left coronary artery arising from the pulmonary artery. Amer. Heart $\mathcal{f}$., 57, 36.

Lampe, C. F. J., and Verheugt, A. P. M. (1960). Anomalous left coronary artery (adult type). Amer. Heart $\mathcal{F}$., $59,769$.

Liebman, J., Hellerstein, H. K., Ankeney, J. L., and Tucker, A. (1963). The problem of the anomalous left coronary artery arising from the pulmonary artery in older children. New Engl. F. Med., 269, 486.

McKinley, H. I., Andrews, J., and Neill, C. A. (1951). Left coronary artery from the pulmonary artery. Pediatrics, 8, 828.

Massih, N. A., Lawler, J., and Vermillion, M. (1963). Myocardial ischemia after ligation of an anomalous left coronary artery arising from the pulmonary artery. Nero Engl. F. Med., 269, 483.
Nadas, A. S., Gamboa, R., and Hugenholtz, P. C. (1964). Anomalous left coronary artery originating from the pulmonary artery. Circulation, 29, 167.

Noren, G. R., Raghib, G., Molter, J. H., Amplatz, K., Adams, P., and Edwards, J. E. (1964). Anomalous origin of the left coronary artery from the pulmonary trunk with special reference to the occurrence of mitral insufficiency. Circulation, 30, 171.

Proescher, F., and Baumann, F. W. (1944). Abnormal origin of the left coronary artery with extensive cardiac changes in a female child thirteen months old. $\}$. Pediat., 25, 344.

Rowe, G. G., and Young, W. P. (1960). Anomalous origin of the coronary arteries with special reference to surgical treatment. f. thorac. Surg., 39, 777.

Rudolph, A. M., Gootman, N. L., Kaplan, H., and Rohman, M. (1963). Anomalous left coronary artery arising from the pulmonary artery with large left-to-right shunt in infancy. F. Pediat., 63, 543.

Sabiston, D. C., Neill, C. A., and Taussig, H. B. (1960). The direction of blood flow in anomalous left coronary artery arising from the pulmonary artery. Circulation, 22, 591.

—, Ross, R. S., Criley, J. M., Gaertner, R. A., Neill, C. A., and Taussig, H. B. (1963). Surgical management of congenital lesions of the coronary circulation. Ann. Surg., 157, 908.

Soloff, L. A. (1942). Anomalous coronary arteries arising from the pulmonary artery; report of a case in which the left coronary artery arose from the pulmonary artery. Amer. Heart f., 24, 118.

Tedeschi, C. G., and Helpern, H. M. (1954). Heterotopic origin of both coronary arteries from the pulmonary artery. Pediatrics, 14, 53. 